\title{
Erratum to: Synthesis, antitubercular activity, and molecular modeling studies of analogues of isoliquiritigenin and liquiritigenin, bioactive components from Glycyrrhiza glabra
}

\author{
Rashmi Gaur ${ }^{1}$. Jay Prakash Thakur ${ }^{2}$ - Dharmendra K. Yadav ${ }^{3}$. \\ Deepak Singh Kapkoti ${ }^{1}$ - Ram Kishor Verma ${ }^{4}$ - Namita Gupta ${ }^{4}$. \\ Feroz Khan $^{3} \cdot$ Dharmendra Saikia $^{2} \cdot$ Rajendra Singh Bhakuni $^{1}$
}

Published online: 31 July 2015

(C) Springer Science+Business Media New York 2015

Erratum to: Med Chem Res (2015) 24:3494-3503

DOI 10.1007/s00044-015-1401-1

After the publication of this work, we were made aware that a part of Table 1 is missing. The complete Table 1 is available with this erratum.

The correction does not affect any results or conclusions of the published work.

The online version of the original article can be found under doi:10.1007/s00044-015-1401-1.

Rajendra Singh Bhakuni

bhakunirs2000@gmail.com

1 Medicinal Chemistry Division, Central Institute of Medicinal and Aromatic Plants (CSIR), P.O.-CIMAP, Kukrail Picnic Spot Road, Lucknow 226015, U.P., India

2 Biotechnology Division, Central Institute of Medicinal and Aromatic Plants (CSIR), Lucknow 226015, India

3 Metabolic and Structural Biology Department, Central Institute of Medicinal and Aromatic Plants (CSIR), Lucknow 226015, U.P., India

4 Analytical Chemistry Division, Central Institute of Medicinal and Aromatic Plants (CSIR), Lucknow 226015, India 
Table 1 Antimycobacterial activity of ISL, LTG, and their analogues against M. tuberculosis $\mathrm{H}_{37} \mathrm{Rv}$ strain by BACTEC-460 assay

\begin{tabular}{|c|c|c|c|c|}
\hline Structure of compounds & $\begin{array}{c}\text { MIC } \\
(\mu \mathrm{g} / \mathrm{mL})\end{array}$ & Physical data & $\mathrm{MP}\left({ }^{\circ} \mathrm{C}\right)$ & $\begin{array}{c}\text { Yield } \\
(\%)\end{array}$ \\
\hline 1 & 25 & Yellow powder & $208-210$ & 0.00056 \\
\hline 2 & 25 & Cream powder & 206-208 & 0.0006 \\
\hline 3 & n.a. & Orange crystals & $91-92$ & 87 \\
\hline 4 & 100 & Light orange crystals & $70-71$ & 91 \\
\hline 5 & 25 & Dark orange crystals & $90-91$ & 96 \\
\hline 6 & 12.5 & Yellow solid & $65-66$ & 93 \\
\hline 7 & 12.5 & White shiny crystals & $118-119$ & 90 \\
\hline 8 & 25 & Yellow powdery crystals & $145-146$ & 8 \\
\hline 9 & n.a. & Yellow crystals & $50-51$ & 92 \\
\hline 10 & 25 & Yellow viscous & Viscous & 83 \\
\hline
\end{tabular}


Table 1 continued

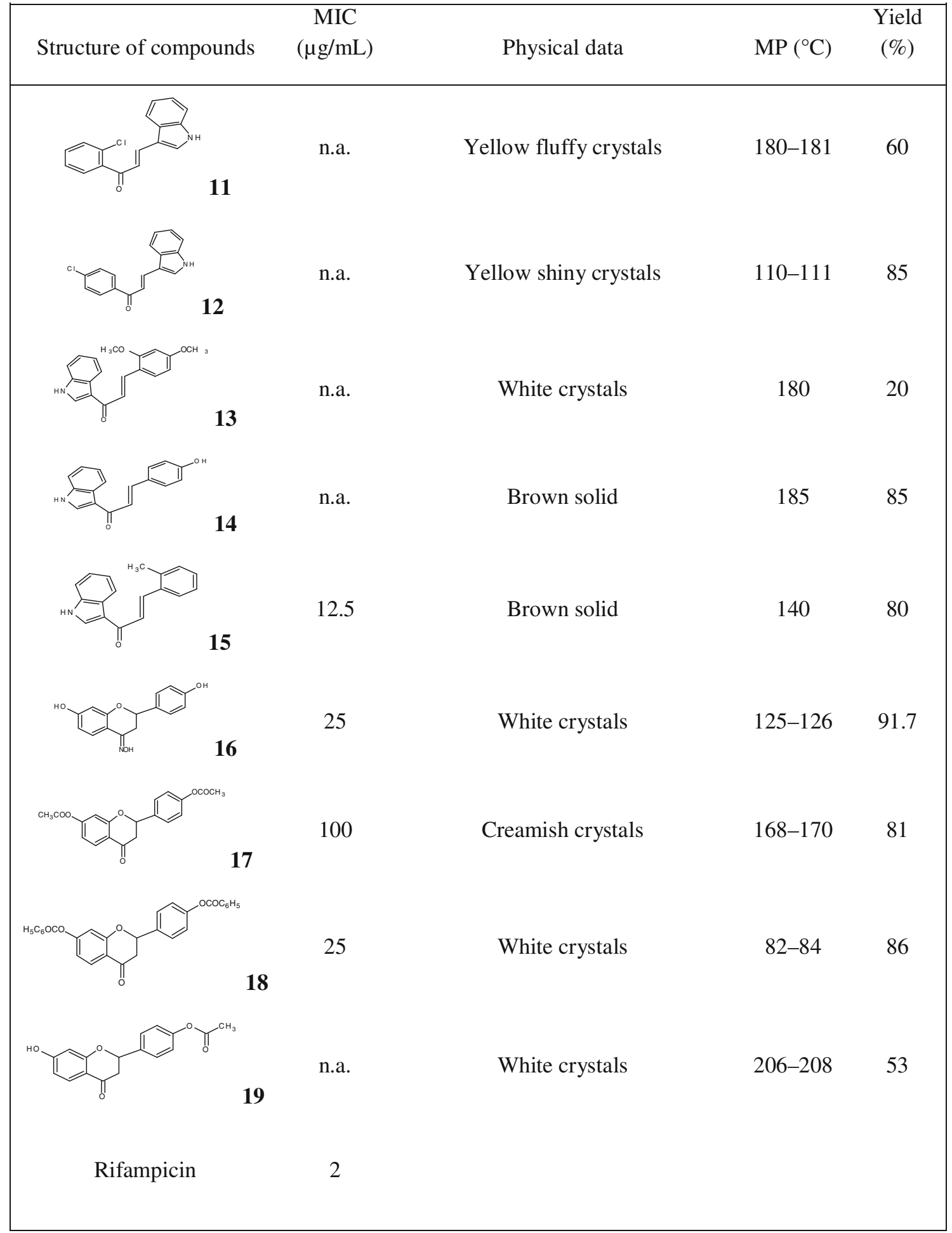

n.a. no activity detected at $100 \mu \mathrm{g} / \mathrm{mL}$ 